\title{
Analysis on the Relationship between Strategic Management of Enterprises and Personality Traits of Entrepreneurs-A Case Study of Shanxi Jiujie Co., Ltd.
}

\author{
Xudong Zhang \\ School of Economics and Management, Southeast University Chengxian College, Nanjing 210088, \\ China
}

1013032675@qq.com

\begin{abstract}
Keywords: small and medium private enterprises; strategic management; personalities of entrepreneurs.
\end{abstract}

\begin{abstract}
In the age of rapid development, the quick development of small and medium private enterprises is closely related to personality traits of leaders. At the same time, however, when many people make evaluation on enterprises, they just focus more on the hardware conditions instead of the effects of entrepreneurs on enterprises. Therefore, effects of personality traits of entrepreneurs on enterprises are worthy of our attention. This thesis makes analysis on a private enterprise through SWOT analysis, as well as tests the CEO of the enterprise by DISC personality test to discuss the relationship between strategic management of enterprises and personality traits of leaders. The study shows that entrepreneurs should have the steady personality to seriously make strategies for enterprises, and they can flexibly make changes, daring to take responsibilities for their own decisions without fearing challenges when they face market risks.
\end{abstract}

\section{Background Review}

Whether small and medium enterprises can break the bottleneck to make rapid development when they face rapid changes of the environment, depends largely on personality traits of entrepreneurs. However, in the developing process, some enterprises today only pay attention to the hardware conditions such as production scale, and the improvement of employees' technical skills, ignoring the effects of personality traits of entrepreneurs. Actually, adopting radical or conservative strategies in the changing environment and choosing to expand production or develop new products in the booming time or the decline stage, are largely pertinent to leaders' personalities in enterprises. Conducting the study between development strategies of enterprises and personality traits of entrepreneurs can give a positive reference to development of enterprises.

Selecting strategies in enterprises and personality traits of entrepreneurs attract broad attention both in academic research and in practice. In consequence, it is necessary to do a research and make a discussion on strategies made by enterprises and personality traits of entrepreneurs in the period of stagnation. However, many problems in different respects occur in this period, and different enterprises have different developing periods while different entrepreneurs make different strategic decisions. For these reasons, the thesis focuses on studying effects of strategic decisions made by different entrepreneurs on enterprises when small and medium enterprises in the same industry develop in the middle and later periods.

The objective of the thesis is to discuss the relationship between development strategies of small and medium private enterprises and personality traits of entrepreneurs, to find the problems and solutions to tackle the relative problems.

\section{Literature Review}

\subsection{Company Strategies}

There are various kinds of definitions for company strategies, but they can be divided into different categories according to the traditional concept and the modern concept. In the field of traditional 
strategies, the definition of the traditional strategies put forward by Professor Porter M. from Harvard Business School is regarded as the representative, considering the strategy is the combination of the goals which enterprises strive for and ways to achieve them.

The modern company strategy was put forward by Mintzberg H., the Canadian scholar in 1989. According to his definition, it is incorrect to treat company strategy as the product of rational plan based on intentional purpose because many successful strategies emerge under the circumstances that without planning. He defines strategy as a series or a set of decisions or ways of actions which include arranged (or planned) strategies and temporary (or unplanned) strategies. Many scholars also begin to study bounded rationality of organizations and stress on the adaptation of organizations under the internal and external constraints which are unpredictable or unknown.

The definition made by Porter shows the universal recognition towards company strategy in the 1960s and 1970s, emphasizing one kind of attribute of company strategy, which includes planning, globality, and chronicity. However, modern strategy more focuses on the other kind of attribute, referring to adaptability, competitiveness and risk. In fact, most of strategies are planned in advance and unplanned out of emergency. In 1998, Tomson S pointed out that strategy is planned (planned strategy) and reactive (adaptive strategy). Only by continuously changing and adjusting to strategies, as well as keeping vigorous, developing healthily, and turning this kind of vigor into long-term energy by effective strategies, can enterprises gain and strengthen competitive advantages to make a great success at last.

\subsection{Personality Traits of Entrepreneurs}

Personality is a kind of steady attitude towards the reality and a kind of personal characteristic which is shown in an accustomed way corresponding to the attitude. As for entrepreneurs, personality may be the precious wealth or the fatal poison. The style and the aura of an enterprise are decided by personalities of an entrepreneur. Private enterprises in China, especially some small and medium enterprises, with history of 20 years to 30 years, are neither equipped with perfect rules, and regulations nor inherited culture, so it is reasonable to view the company management from personalities of leaders. It is often said that personality is life and attitude is life, which can also be applied to company management. There are many factors leading to ways that enterprises handle affairs, but the core one lies on personalities of entrepreneurs.

According to the study of characterology of entrepreneurs in Business Observer by Fang Ge, personality traits of entrepreneurs can be divided into flexible entrepreneurs and steady entrepreneurs. Flexible entrepreneurs are prompt, passionate and sensitive to knowing the environment and selecting a market, having awareness of innovation, preferring distinctive way of management and treating employees kindly, such as Ding Lei, CEO from Net ease, and Zhang Chaoyang, CEO from Sohu. Steady entrepreneurs, calm, cautious, and rational, manage their enterprises step by step, focusing on the establishment of their own brands with the notion of permanent management, preferring humanized managing approaches. This kind of entrepreneurs, very thoughtful, can seize good opportunities to strike back after being struck, tackling problems in an easy way. Personalities of entrepreneurs can be changed and company management can be improved gradually based on the governance system of modern enterprises. But as for small and medium enterprises, the systematic management has failed to penetrate in people's minds. What spiritual characteristics should entrepreneurs have? In Chinese and Foreign Entrepreneurs, $\mathrm{Li}$ Wenhui pointed out that an entrepreneur needs not only the spirit of working in earnest as a leader, but also the broad knowledge, the ability of organizing and managing, and some good personalities. Personality traits of entrepreneurs have a common standard, which are shown in the research table made by Zhao Yanjun and Wang Xiaoming in Characters of Entrepreneurs. There are many characters accounting for more than $90 \%$, including fearless of risks, firm and persistent, positive, broad-minded, confident, undisturbed, innovative, and hardworking, which can be seen that a good entrepreneur firstly should be fearless of risks, then firm and persistent, and finally confident and undisturbed by the external world. 
Table 1. Analysis and Investigation on Personality Traits of Entrepreneurs

\begin{tabular}{|c|c|c|c|c|c|c|c|c|c|c|c|}
\hline \multicolumn{3}{|c|}{$\begin{array}{l}\text { Manner characteristics on } \\
\text { temperament }\end{array}$} & \multicolumn{3}{|c|}{$\begin{array}{l}\text { Volitional characteristics of } \\
\text { character }\end{array}$} & \multicolumn{3}{|c|}{$\begin{array}{l}\text { Emotional characteristics of } \\
\text { character }\end{array}$} & \multicolumn{3}{|c|}{$\begin{array}{l}\text { Rational characteristics of } \\
\text { character }\end{array}$} \\
\hline \multirow{3}{*}{$\begin{array}{l}\text { Sense of social } \\
\text { responsibility }\end{array}$} & Strong & 31 & \multirow{3}{*}{ Consciousness } & Strong & 86 & \multirow{3}{*}{$\begin{array}{l}\text { Energy and } \\
\text { enthusiasm }\end{array}$} & Good & 51 & \multirow{3}{*}{ Undisturbed } & Good & 95 \\
\hline & Common & 55 & & Common & 11 & & Common & 45 & & Common & 3 \\
\hline & $\begin{array}{c}\text { Not } \\
\text { strong }\end{array}$ & 14 & & $\begin{array}{c}\text { Not } \\
\text { strong }\end{array}$ & 3 & & $\mathrm{Bad}$ & 4 & & $\mathrm{Bad}$ & 2 \\
\hline \multirow{3}{*}{ Hard working } & Good & 92 & \multirow{3}{*}{ Possessiveness } & Strong & 51 & \multirow{3}{*}{$\begin{array}{l}\text { Emotional } \\
\text { stability }\end{array}$} & Good & 61 & \multirow{3}{*}{$\begin{array}{l}\text { Active } \\
\text { memory }\end{array}$} & Good & 81 \\
\hline & Common & 8 & & Common & 33 & & Common & 31 & & Common & 15 \\
\hline & $\mathrm{Bad}$ & 0 & & $\begin{array}{l}\text { Not } \\
\text { strong }\end{array}$ & 16 & & $\mathrm{Bad}$ & 8 & & $\mathrm{Bad}$ & 4 \\
\hline \multirow{3}{*}{ Confident } & Strong & 96 & \multirow{3}{*}{ Endurance } & Strong & 98 & \multirow{3}{*}{$\begin{array}{l}\text { Emotional } \\
\text { endurance }\end{array}$} & Good & 87 & \multirow{3}{*}{$\begin{array}{l}\text { Thinking } \\
\text { innovation }\end{array}$} & Good & 93 \\
\hline & Common & 4 & & Common & 2 & & Common & 11 & & Common & 6 \\
\hline & $\begin{array}{c}\text { Not } \\
\text { strong }\end{array}$ & 0 & & $\begin{array}{c}\text { Not } \\
\text { strong }\end{array}$ & 0 & & $\mathrm{Bad}$ & 2 & & $\mathrm{Bad}$ & 1 \\
\hline \multirow{3}{*}{ Risk } & Fearless & 98 & \multirow{3}{*}{ Decisiveness } & Strong & 89 & $\begin{array}{l}\text { Optimism } \\
\text { and open- } \\
\text { minded }\end{array}$ & Good & 97 & \multirow{3}{*}{$\begin{array}{c}\text { Active } \\
\text { imagination }\end{array}$} & Good & 82 \\
\hline & Common & 1 & & Common & 8 & & Common & 3 & & Common & 16 \\
\hline & Fear & 1 & & $\begin{array}{c}\text { Not } \\
\text { strong }\end{array}$ & 3 & & $\mathrm{Bad}$ & 0 & & $\mathrm{Bad}$ & 2 \\
\hline
\end{tabular}

\subsection{The Relationship between Company Strategy and Personality Traits of Entrepreneurs}

Since reform and opening up, most of small and medium private enterprises have not formed perfect rules and regulations without cultural inherence. Therefore, a strategic choice is related to personality traits of entrepreneurs. There are two kinds of characters of entrepreneurs in general, flexible one and conservative one. Flexible entrepreneurs work in emerging industries, using modern company strategy while conservative entrepreneurs tend to use traditional strategies, working in traditional industries. Emerging industries occur in new sections and industries with the development and application of researching results and new technologies. The main stream of emerging industries refers to a series of new sections and industries with the development of electronics, information, biology, new materials and so on. Leaders in these enterprises in emerging industries, are required to use the modern company strategies to face the great progress in the field of technology, most of who are flexible, active in thinking and sensitive to changes of the environment. Shao Honglun and $\mathrm{Li}$ Xuefeng put forward in the article that emerging enterprises face competitions from those enterprises in the same industries, and uncertainty of the market. Different industries do not share information with each other, and enterprises in the same industries emerge continuously, so daring to reform, seeking expansion and making innovation are important conditions to manage talents.

However, traditional industries are labor intensive, mainly in manufacture, such as shoemaking industry, clothing industry, machinery industry, manufacturing industry, steel and coal industries and so on. All leaders in these traditional industries are steady, most of who use traditional company strategy, and make the long-term plan for the future, are more conscious when handling things because a little change in quantity of cargo may greatly affect profits of an enterprise. If enterprises are supposed to be stable and then make development, they may be stable in a short term, but there are many problems occurring such as outmoded products in a long term. In A Comparative Study between Traditional Management and Modern Company Management, Yang Yang, indicated that from the view of traditional company management, economic benefits of enterprises are from production of products, so it is a matter of course to give priority to quantity and output value. Due to the emphasis on management in production, the center focused by leaders is the producing process instead of operating decisions, product designs and product innovation. Therefore, it can be found that personalities of entrepreneurs make great influences on developing directions of enterprises. Conservative entrepreneurs work in traditional industries, insist on the traditional company strategy while flexible entrepreneurs who often implement the modern company strategy, mostly work in emerging industries with passion, and creativity, daring to challenge themselves. Nevertheless, the two kinds of ways of management both have advantages and disadvantages, which should complement with each other.

In the article, A Comparative Study on Traditional Management and Modern Company Management, Yang Yang demonstrated that facing the rapid development, enterprises not only need to keep the steady mind for a long time and to avoid mistakes as possible as they can, but also need 
to be competitive, making adjustment of their arrangement at any time according to change of time, and environment. That is to say, those steady entrepreneurs are also supposed to think flexibly while those flexible entrepreneurs need to be stable and down-to-earth. These two kinds of entrepreneurs both need to combine the traditional company strategy with the modern company strategy and analyze problems from a long-term view, tackling things at any time. An excellent entrepreneur should know their own personality traits, dare to seize opportunities and take a risk when facing new opportunities, but in the period of taking a risk, thinking considerately, and facing challenges and opportunities steadily are characters that an entrepreneur should have. Moreover, an excellent entrepreneur also should fully affirm and carry out the strategies made before.

\subsection{SWOT Analysis}

SWOT Analysis, also called situation analysis, lists internal strengths, weakness, external opportunities and threats by investigations, arrays these factors in matrix form, and use methods of system analysis to match each factor, which result in a series of decision- making conclusions to some extent.

By this approach, the study can make a comprehensive, systematic, and accurate research about the situation of the research object, which leads to relevant development strategies, plans and measures based on research results. SWOT Analysis tends to be used to make development strategies of enterprises and analyze situations of their competitors, regarded as one of the most common methods in strategic analysis.

\subsection{DISC Personality Test}

The theory of DISC is the language of human behaviors, the theoretical basis of which is the book released in 1928, Emotions of Normal People written by Dr. William Moulton Marston, the American psychologist who studied identifiable, and normal human behaviors. According to DISC, human personalities are divided into four categories.

Table 2. DISC theory, personality classification

\begin{tabular}{|c|c|}
\hline Dominance & The Director \\
\hline Influence & The Interact \\
\hline Steadiness & The Supporter \\
\hline Conscientiousness & The Corrector \\
\hline
\end{tabular}

\section{The Basic Situation and Strategic Evaluation of Shanxi Jiu Jie Co., Ltd.}

\subsection{The Introduction of Basic Situation of Shanxi Jiu Jie Co., Ltd.}

Jiu Jie Security Electronic Co., Ltd. in Jin Cheng mainly works on projects in the field of coal safety with more than 30 employees, including 20 technicians, and 5 managers. The company always takes safety in production of coal and social stability as its duties based on the scientific attitude of making perfection more perfect, keeping the principle that giving priority to science and technology, as well as brand in accordance with four development notions, integrity, corporation, truth seeking, and innovation to continuously attract technological talents and to enhance its service quality.

\subsection{SWOT Analysis on Strategies of Shanxi Jiujie Co. Ltd.}

\subsubsection{There are Many Competitive Strengths of Shanxi Jiujie Co. Ltd.}

Firstly, it has the strengths of talents and technology. The company has a good ability of construction with strong technology, having the level-1 qualification certification in the field of construction awarded by the public security sector in Shanxi province. In 2009, the company passed GB/T9001-2008/ISO9001, which was certificated by QMSC in 2008. Additionally, Jiujie also has a lot of learned, experienced and skillful talents who graduate from majors relevant to businesses of the company. The CEO has many similar characters with those mentioned in Personality Traits of Entrepreneurs by Wang Xiaoming. In the interview, the CEO emphasizes that he dares to take risks and he also knows how to correct mistakes after making them. But he also chooses to insist on his business with fearless of risks without caring about others' view. 
Secondly, it has economic strengths with an opened market. Cooperated with energy-based companies in the coal industry for a long time, knowing consumers' behaviors, the company has unique and rich experience of exploring the market and sales business owe to long time establishment. Additionally, it also has the good relationship with suppliers and the mature supplying network, so the supply of commodities is always in time. With the fixed supplier, the company forms a good sales service system.

Thirdly, as the local enterprise, the company has a good understanding of the market and trends of the market. In recent years, because of the recession of the coal market, the company chooses to use conservative strategies, developing steadily. However, in seasons of autumn and winter, the demand of coal increases sharply, thus the company adopts competitive strategies to expand its market and gain bigger orders with the hope of making the profits maximum.

\subsubsection{There Also Exists Competitive Weakness in Shanxi Jiujie Co., Ltd.}

The major problem of the company is without independent products. It shows in many aspects.

Firstly, its ability of bargaining with suppliers is weak. Because the supply is less than the demand in the market, suppliers who can produce security products are few. Moreover, for the reason that these security products belong to precise instruments, the production quantity is limited, which results in a comparative high price.

Secondly, the company is not able to produce equipments, but security equipments are precise instruments. Due to high requirements of technology in production and talents, a large amount of money is needed to invest. Jiujie is a private company in small size without much idle fund to produce equipments for self-efficiency.

Thirdly, its weakness is related to brand effects. Although Jiujie can produce relevant instruments, consumers always appoint those products produced by famous manufacturers, which may enhance the bargaining power of suppliers. Therefore, one of the most important factors making its cost hard to decline is the failure of having its own products.

Fourthly, the company adopts family-run management. Under these circumstances, people may have disputes on the matter of power, so when they have opportunities, they do not quickly make a decision, missing the best chance. In addition, the educational level of company leaders is not as high as those professional managers, which leads to many problems in a decision. What's more, there are many members in a family. That is to say, when people deal with affairs, they tend to care about feelings of families, whose sensibility is more than reason, which may excite contradictions. In Effects of Personality Traits of CEO on Formation and Operation of the Manager Group, Liu Haishan and Sun Haifa indicate that some entrepreneurs who operate private enterprises lack long-term vision, always arbitrary, seeking opportunities to gain excessive profits, affected by personal experience and educational levels. In consequences, they ignore the improvement of the ability of operation, and the optimization of management system, failing to establish the modern management system.

\subsubsection{Opportunities in Shanxi Jiujie Co., Ltd are as Following.}

Firstly, recovery of the market is the opportunity. Many cooperative enterprises are energy-based industry of coal. Whether the industry can make profits shows the ability of Jiujie. After the period of prosperity in the coal industry, the production of coal so outstrips the demand that the price of coal rapidly drops.

In this period, a part of coal industry stops its production, and security equipments decline relatively, which shrink the market. However, since the government began to govern the coal industry, advocating people to use environmental energy, coal enterprises have been integrated and improved, and at the same time, the supply of coal has reduced, which enhance their ability of bargaining. Besides, in this winter, the supply of a new energy is less than the demand, exploring the large market in the coal industry, so the price increases, and more opportunities begin to emerge. Consumers of Jiujie need new security equipments to assist their productions, and then the market starts to recover.

Secondly, the government enhances the security supervision of companies. In recent years, because some companies want to pursue the maximum profits, they save money during the process of the installation of security equipments. In the meanwhile, many accidents happen frequently. The government increases the supervision of security equipments, so enterprises need to install security 
equipments to make prevention and surveillance to their productions, which provide a big market to Jiujie.

Thirdly, the CEO realizes that the bottleneck of the company is a lack of its own products, and the benefits of the coal industry decline continuously, which give rise to the drop of business volume.

Therefore, Jiujie makes good use of the surplus cash flow to invest on the e-commerce medical platform in other provinces. In recent years, e-commerce has developed rapidly, making people's life so convenient that people can do many things online without going outside such as shopping online. Medical platforms can also follow the trend of e-commerce, developing in this form. Thereby, the company can produce its own products, gaining the core competence by seizing opportunities.

\subsubsection{Threats that Shanxi Jiujie Co., Litd. Faces are as Following.}

Firstly, as for economic factors, with more and more suppliers join the marketing competition, many suppliers prefer to install equipments by themselves instead of hiring some companies which gain profits by installment like Jiujie. However, professional staffs of suppliers and their skills of using equipments are hardly caught up by Jiujie. What's worse, some leaders of the same industry use the low-price strategy and give a large discount for their clients to force small and medium enterprises to leave the competition in advance because of the high operating cost.

Secondly, there exists political and law factors. Laws and regulations in our country stipulate energy conservation and emission reduction. The majority of clients of the company are enterprises of energy development of coal, which are the benefit sources to Jiujie. This year, however, because of the emergence of new emerging enterprises and the emphasis on environmental protection by the government, energy-based enterprises in the coal industry benefit less than before and even go out of business, which make Jiujie get into troubles such as the decline of clients, and demand. Naturally, many problems about benefits occur.

Thirdly, the company is also threatened by internal management. The family-run management gives rise to the failure of decision making on account of irritable CEO who usually quarrels with families, and the dispute on power. At this time, other managers in the company will form their own groups. For example, the leader of Jiujie pays much attention to the affection of families, so he appoints his relatives in some positions. Although the ability and personalities of his brother-in-law cannot be competent at the job, CEO of the company, forced by his wife, does not appoint others to replace him, resulting in chaos in Jiujie's management. Additionally, its efficiency is lower and the projects are not completed in time, which affect the integrity and the image of the company, making it hard to remain good relationship with clients.

\subsection{Personality Traits of CEO in Shanxi Jiujie Co., Ltd.}

The report of personality traits of CEO in Jiujie tested by DISC shows that CEO of the company belongs to dominance, characterized by persistence in his career, determination in dealing with matters and bold and candid personalities. Based on the interview about the CEO, it can be found that in the past, the personality of CEO is irritable, strict to his works. When he becomes older, his character becomes mild and gentle, thinking of things comprehensively and practically. Under the management by this CEO, the company adopts modern strategies, combining the company with the competitive environment. With changes of the environment, when the company faces the bottleneck, competitive enterprises are more than before, so benefits and business volume decrease. Fortunately, the CEO chooses to invest on other emerging industries, optimizing the resource distribution and renewal of the company. Finally, benefits of the company reach maximum, which helps the company get out of troubles in the shortest time.

\section{Strategic Analysis and Suggestions on Solutions of Shanxi Jiujie Co., Ltd.}

\subsection{Main Factors of the Emergence of Problems}

There are many internal factors. Although it is the family-run company, the CEO is overconfident, insisting on his own thoughts without adopting others' suggestions. In the company, due to the large power, the CEO considers that his position is the highest and excessively uses his power. However, the form of family-run company tends to lead to some disputes on a series of matters, which attacks 
the thoughts of the CEO. When families debate vehemently, internal members will be divided into two groups, affecting the efficiency of the operation of Jiujie.

In addition to some internal factors, external factors also exist. The CEO is willing to challenge and take a risk, daring to seize a new opportunity bravely. When the market of coal becomes sluggish, the CEO puts forward the idea of transformation without conducting some researches. He invests a certain amount of funds, but he does not know whether the company can make profits. Due to the outward investment, it is hard to invest on resources when the coal market has recovered in recent years. It means that the company loses the best opportunity.

\subsection{Suggestions on Solutions}

In A Study on Centralization and Decentralization on Companies' Management, Huang Changjiang and Tang Na mention that the weakness of centralization is giving too much power to leaders because the ability and energy of a leader is limited, it is hard for whom to consider a problem about development of a company. They also point out that when power of a company is totally charged by one person, it is easy o give rise to inestimable losses because of CEO's selfish interest. However, decentralization is also an extreme management system. If power of a company is shared by its members, the objective of a part of people is against the whole purpose of the company, resulting in conflicts. In the meanwhile, benefit conflicts also occur, so the operating efficiency is low. The solution to solve this problem is combining the system of centralization with the system of decentralization and learning from General Electric Company in America. CEO can be mainly in charge of financial affairs, personnel, and R\&D in a company. Promotion decisions, labor relations and relations of production can be endowed to other staffs in a company. Therefore, all these solutions can help to restraint CEO's excessive usage of power.

\subsection{Thoughts on Problems in Strategies Made by Shanxi Jiujie Co., Ltd.}

The strategic problems of Jiujie occur in the internal power and the external environment. CEO cannot always choose to make transformation of investment rather than take advantages of characteristics of the company when the external market is sluggish. It is also necessary for the CEO to do investigations and researches about unfamiliar industries as well as listen to others' views. The CEO is not supposed to excessively use his own power because it will give rise to internal conflicts and affect the operating efficiency of the company.

\section{The Enlightenment of Making Company Strategies}

When entrepreneurs make a company strategy, they need to analyze the effects of their personality traits on the company strategy. Before finishing, they are supposed to discuss with internal members to prevent excessive centralization. A company strategy is not decided by one person. There are differences between entrepreneurs, especially in their personalities, but a good company strategy is distinct. If leaders want to make suitable strategies, they need to read more books about management, or learn from other entrepreneurs with different personality traits, knowing that when they are confronted with these problems, how to solve them. During the period of steady development, CEO should go to a better platform such as business school, receiving a better education in management, which can improve the theoretical knowledge. It is good for operating a company by using knowledge that learnt before, and effects of one's personality on a company can reach the minimum

\section{Conclusion}

Though personality traits of entrepreneurs are different, classified into flexible entrepreneurs and steady entrepreneurs, during the process of operating enterprises, they are supposed to be both flexible and steady to operate enterprises successfully. Firstly, entrepreneurs should make decisions steadily. Secondly, when they receive stable cash flow after decisions, entrepreneurs need to become flexible and dare to develop new business fields when they face risks in the market, which requires these leaders to take responsibilities bravely without being afraid of risks. They key to sustainable development is entrepreneurs' encouragement to reform when they face a bottleneck of an enterprise. 


\section{References}

[1]. Fangge, Business Observer, 2012.

[2]. Li Wenhui, Chinese and Foreign Entrepreneurs, 1989.

[3]. Zhao Yanjun, Wang Xiaoming, Personalities of Entrepreneurs, 2008.

[4]. Li Xue Feng, Discussion on development of enterprises and talents management, 2012.

[5]. Liu Haishan, Sun Haifa, Effects of Personality Traits of CEO on Formation and Operation of the Manager Group, 2008.

[6]. Tang Na, A Study on Centralization and Decentralization on Companies' Management, 2014.

[7]. M. M. William, Emotions of Normal People, 1928. 